\title{
Rift Valley fever virus: a serological survey in Libyan ruminants
}

\author{
Abdusalam Sharef Mahmoud ${ }^{1,2,3,{ }^{*}}$, Daria Di Sabatino ${ }^{1}$, Maria Luisa Danzetta ${ }^{1}$, Federica Iapaolo $^{1}$, Francesco Tolari ${ }^{3}$, \\ Mario Forzan ${ }^{3}$, Maurizio Mazzei ${ }^{3}$, Abdunaser Dayhum ${ }^{2,4}$, Fabrizio De Massis $^{1}$ and Federica Monaco ${ }^{1}$ \\ ${ }^{1}$ Istituto Zooprofilattico Sperimentale dell'Abruzzo e del Molise "G. Caporale”, (IZSAM), Teramo, Italy \\ ${ }^{2}$ Department of Preventive Medicine, Faculty of Veterinary Medicine, University of Tripoli, Tripoli, Libya \\ ${ }^{3}$ Department of Veterinary Science, University of Pisa, Pisa, Italy \\ ${ }^{4}$ National Center of Animal Health, Tripoli, Libya
}

\begin{abstract}
A serological survey was carried out in Libya to investigate the circulation of Rift Valley fever virus (RVFV) among domestic ruminants. A total of 857 serum samples were collected from year 2015 to 2016 in eleven provinces of Libya belonging to five branches of the country. Samples were tested for RVFV antibodies using a competitive EnzymeLinked Immunosorbent Assay (c-ELISA). Antibodies specific for RVFV were not detected in any of the 857 samples. However, a statistical analysis was carried out to assess the maximum expected number of infected animals and the maximum expected prevalence of RVFV among Libyan ruminants' populations according to the sampled population. The overall maximum expected prevalence was estimated to be $1.8 \%$ for cattle and $0.4 \%$ for small ruminants. Results seem to exclude the circulation of RVFV, however, a surveillance plan should be implemented in areas at risk of RVFV introduction.
\end{abstract}

Keywords: c-ELISA, Libya, RVF, Sero-prevalence.

\section{Introduction}

Rift Valley fever (RVF) is an acute arthropod-borne zoonotic disease caused by a Phlebovirus belonging to the family Bunyaviridae. Although direct transmission (contact with infectious animals or animal tissues) might occur and plays a significant role in the human infection, mosquitoes usually represent the most common way for viral transmission (Abdo-Salem et al., 2011; EFSA, 2013) among a wide range of domestic and wild ruminant hosts.

The number of competent RVF vectors is far to be defined, at least 30 species of mosquitoes have been found infected in course of outbreaks (Meegan and Bailey, 1988; Fontenille et al., 1998) or have demonstrated their capability to transmit the virus in laboratory conditions (Pages et al., 2009). However, a crucial role in the occurrence of RVF is played by mosquitoes belonging to Aedes, Culex and Anopheles genera (Smithburn et al., 1948; Meegan et al., 1980; Davies et al., 1985).

RVF is endemic in most of the sub-Saharan territories (Meegan, 1979; Aradaib et al., 2013) with different cyclic reoccurrence usually associated to exceptionally heavy rains and floods (Mondet et al., 2005; Abdallah et al., 2016) leading to severe epidemics with human and animal fatalities (Caminade et al., 2014). The same devastating consequences are known to occur every time the virus spread outside the traditional endemic territories as reported in Egypt (Kamal, 2011), in Saudi Arabia and Yemen (Madani et al., 2003).

The capability of the virus to infect a huge variety of vertebrate hosts coupled with its capability to be transmitted by a wide range of potential vectors (e.g. Aedes vexans, Aedes albopictus, Ochlerotatus caspius, Ochlerotatus detritus, Culex pipiens, Culex theileri, Culex perexiguus, Culex antenantus, Culex tritaeniorhynchus) poses RVF virus (RVFV) as one of the major threat for Mediterranean territories (EFSA, 2013). Eventhough RVF has been described in Egypt and is considered endemic in Mauritania (Faye et al., 2014), nevertheless, the viral circulation has never been reported in the ruminant population of the Maghreb region (Ayari-Fakhfakh et al., 2011).

The aims of this study were, firstly, to investigate the sero-prevalence of RVF in cattle, sheep and goats of eleven Libyan provinces belonging to five Branches (Green Mountain, Benghazi, Tripoli, West Mountain, Sabha) of the country, secondly to assess the maximum number of positive animals and RVF sero-prevalence that could be expected according to the sampled population.

\section{Material and Methods}

During the 2015-2016 period, 171 cattle and 686 small ruminants sera were collected from domestic ruminants in 96 farms located in eleven provinces distributed in five regions of Libya (Fig. 1). 


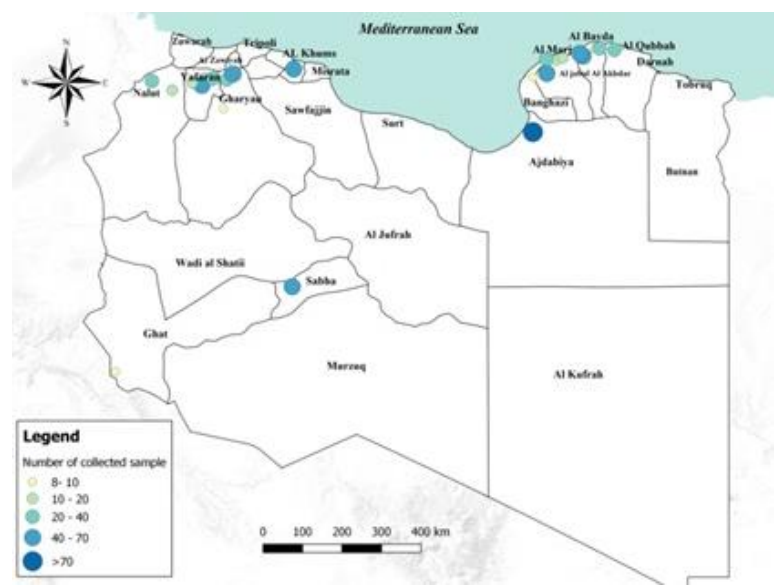

Fig. 1. Number of collected samples (small and Large ruminants) represented by sampled areas and sample size classes in Libya.

In each farm a maximum of 10 serum samples were gathered regardless the herd size. Unfortunately, the socio-political particular situation in the country limited the possibilities of samples collection to suitable and easily accessible provinces within each region, therefore, the criteria used for sampling strategy may have biased the representativeness of data in a number of the provinces tested.

To investigate the sero-prevalence of RVF, all the samples were tested with a competitive EnzymeLinked Immunosorbent Assay (c-ELISA) commercially available according to the manufacturer's protocol (ID screen ${ }^{\circledR}$ Rift Valley Fever Competition Multi-species, IDvet, Grabels, France).

The maximum expected prevalence of antibodies against RVFV (a) and the maximum number of positive animals among cattle and small ruminants (b) for each province were estimated with the statistical approach described by Cannon and Roe (1982), based on the following formulae:

a) $\quad \mathrm{P}=1-(1-\alpha) 1 / \mathrm{n}$

b) $\left.\quad D=\left[1-(1-\alpha)^{1 / n}\right][N-n / 2)\right]+1$

Where $\mathrm{N}=$ number of individuals in a population, $\mathrm{n}=$ number of samples, $D=$ the maximum number of positive individuals, $\mathrm{P}=$ the maximum expected prevalence of RVF in the target population and $\alpha=$ the desired confidence level (95\% used).

\section{Results and Discussion}

Antibodies against RVFV were not detected in any of the 857 sera tested. Therefore, the overall maximum expected prevalence of RVF was estimated at $1.8 \%$ for cattle and $0.4 \%$ for small ruminants, which lead to the estimation of not more than 1,875 positive cattle and not more than 13,869 positive small ruminants in the Libyan population (FAO, 2018) (Table 1 and Fig. 2). The interpretation of the statistical analysis results should take into account the efforts in collecting samples under the peculiar country's situation resulting in a non-random sampling, which may lead to a certain level of bias in the observed results.

The circulation of RVFV has never been reported in Libya neither in humans nor in livestock populations. Thus, the lack of any serologically reactive ruminant among the 857 samples from the 11 provinces included in the study was to some extent expected. The negative result obtained from the serological survey may also be ascribed to the performances of the test used to screen the sera even though the sensitivity of the assay has been considered satisfactory with domestic ruminant sera (Monaco et al., 2015).

Even if the RVFV circulation in Libya could be excluded in the period considered, nevertheless, the results should be carefully evaluated since it is well known that the virus is endemic in many of the bordering countries as Egypt (Mroz et al., 2017), Sudan (Hassan et al., 2011) and Niger (WHO, 2016), where the viral activity has been documented.

However, no outbreaks of RVF were notified during the study period in these countries. It is well known that RVFV environmental cycle is characterized by interepidemic periods (IEPs) with no apparent viral circulation, lasting even for decades (LaBeaud et al., 2008; Lichoti et al., 2014). During IEPs the occurrence of clinical manifestation of the disease is often absent and the low-level enzootic circulation in livestock could be detected by active surveillance activities, mainly relying on the use of sentinel ruminants (LaBeaud et al., 2008; Rissman et al., 2016; Mroz et al., 2017).

Thus, to prevent the potential spread of the disease from bordering regions it would be advisable to focus the surveillance activities in the areas at risk for RVFV introduction. In particular, the Southern part of Libya is the theatre of an intense animals movement, often uncontrolled or with fragile quarantine measures.

The lack of any report referring RVFV circulation in Libya supports the negative results obtained during the study period, as well as the lack of an appropriate sampling strategy could represent a weak point in the serological survey. Even though we are aware of these limits linked to the political instability of the country, we consider the obtained results may be of value for understanding the RVF epidemiological situation in Libya.

\section{Conclusion}

This study was conducted to investigate the epidemiological situation of RVFV in Libya. The viral circulation has not been detected in 11 provinces of the country as determined by absence of RVFV antibodies in animals tested during the sampling period. However, the evidence of RVFV activity in countries bordering the Southern part of Libya supports the hypothesis of a continuous risk of introduction of RVFV through animals imported from endemic neighbor countries. 
Table 1. Detail of the maximum number of infected animals and the maximum expected sero-prevalence of RVFV by province and species in Libyan ruminant population.

\begin{tabular}{clcccccccc}
\hline \multirow{2}{*}{ Province ID } & \multirow{2}{*}{ Province name } & \multicolumn{4}{c}{ Cattle } & \multicolumn{3}{c}{ Sheep and Goats } \\
\cline { 2 - 9 } & & Population & Tested & MI & MSP(\%) & Population & Tested & MI & MSP(\%) \\
\hline 1 & Ajdabiya & 75 & 10 & 19 & $25.9 \%$ & 400,000 & 88 & 13,387 & $3.3 \%$ \\
8 & Al Marj & 61,861 & 29 & 6,071 & $9.8 \%$ & 580,000 & 61 & 27,795 & $4.8 \%$ \\
9 & Al Marqab & 8,611 & 70 & 360 & $4.2 \%$ & 495,135 & 0 & nc & nc \\
10 & Al Qubbah & 8,225 & 7 & 2,863 & $34.8 \%$ & 220,000 & 25 & 24,844 & $11.3 \%$ \\
3 & Benghazi & 13,315 & 24 & 1,562 & $11.7 \%$ & 880,000 & 134 & 19,455 & $2.2 \%$ \\
19 & Gharyan & 1,050 & 0 & nc & nc & 57,829 & 100 & 1,706 & $3.0 \%$ \\
22 & Mizdah & 0 & 0 & nc & nc & 153,000 & 10 & 39,606 & $25.9 \%$ \\
24 & Nalut & 120 & 0 & nc & nc & 192,554 & 60 & 9,377 & $4.9 \%$ \\
\hline 25 & Sabha & 2,000 & 0 & nc & nc & 185,000 & 48 & 11,193 & $6.1 \%$ \\
32 & Yafran - Jadu & 117 & 10 & 30 & $25.9 \%$ & 94,563 & 131 & 2,137 & $2.3 \%$ \\
\hline 4 & Al-Jabal Al-Akhdar & 15,793 & 21 & 2,099 & $13.3 \%$ & 420,000 & 29 & 41,220 & $9.8 \%$ \\
\hline & Total & 111,167 & 171 & 1,875 & $1.7 \%$ & $3,678,081$ & 686 & 13,869 & $0.4 \%$ \\
\hline
\end{tabular}

(MI): Maximum number of infected animals; (MSP): Maximum expected sero-prevalence; (nc): Not calculable.

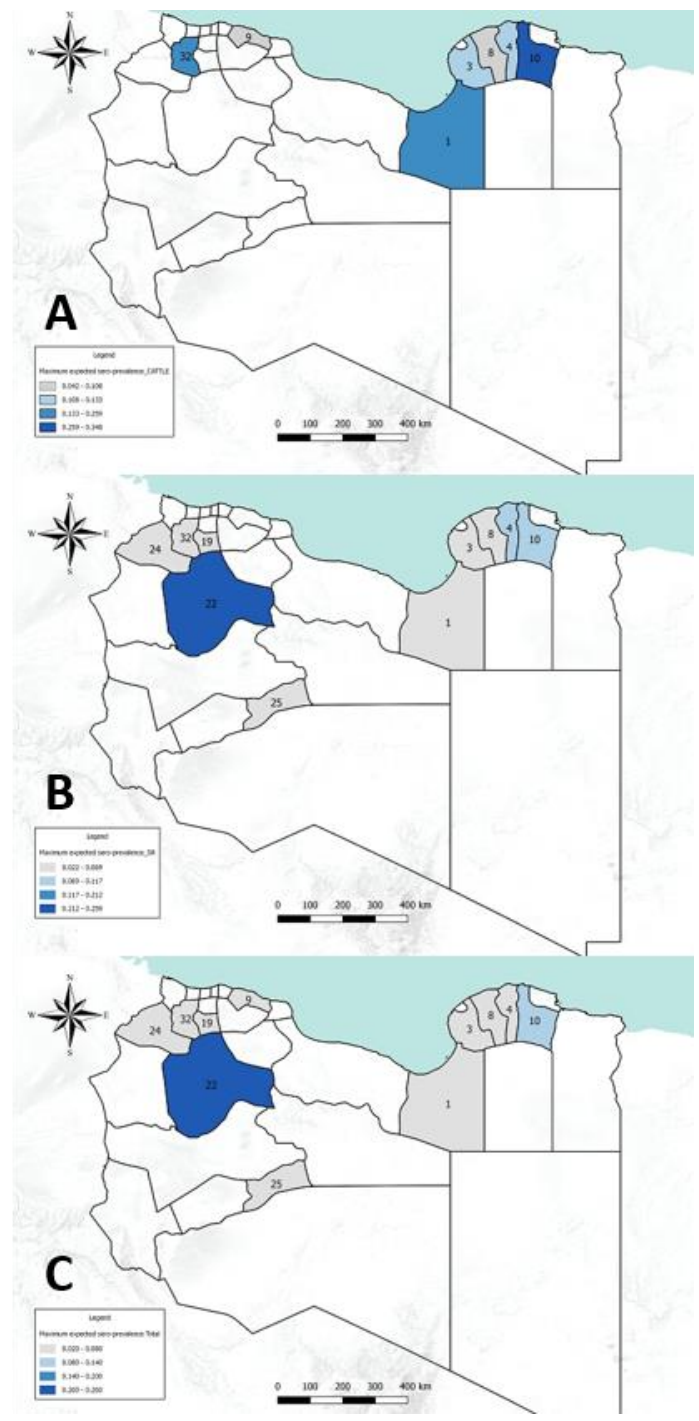

Fig. 2. Maps of maximum expected sero-prevalence by Provinces (the numbers indicated ID provinces in Table 1). (A): Cattle. (B): Small ruminants. (C): Total maximum expected sero-prevalence for small and large ruminants.
Future surveillance activities and animals movement control should be foreseen in the areas at risk, i.e. where imported animals and vectors population may create the environmental suitable condition for RVFV circulation.

\section{Acknowledgements}

The authors would like to express their appreciations to staff of the Libyan National Center for Animal Health (NCAH) for their collaboration, facilitating and samples sending in time, especially to those who contributed in collecting samples and filling questionnaires. The authors would like to express their gratitude to the staff of the National Reference Centre of Istituto Zooprofilattico Sperimentale dell' Abruzzo e del Molise G Caporale (IZSAM), Teramo, Italy, for providing fund and samples testing.

\section{Conflict of interest}

The Authors declare that there is no conflict of interest.

Abdallah, M.M., Adam, I.A., Abdalla, T.M., Abdelaziz, S.A., Ahmed, M.E. and Aradaib, I.E. 2016. A survey of rift valley fever and associated risk factors among the one-humped camel (Camelus dromedaries) in Sudan. Ir. Vet. J. 69, 6. doi: 10.1186/s13620-016-0065-6.

Abdo-Salem, S., Tran, A., Grosbois, V., Gerbier G, AlQadasi, M., Saeed, K., Etter, E., Thiry, E., Roger, F. and Chevalier, V. 2011. Can Environmental and Socioeconomic Factors Explain the Recent Emergence of Rift Valley Fever in Yemen, 20002001? Vector Borne Zoonotic Dis. 11(6), 773-779.

Aradaib, I.E., Erickson, B.R., Karsany, M.S., Khristova, M.L., Elageb, R.M., Khidir, I.E., Karrar, A.E. and Nichol, S.T. 2013. Rift Valley fever, Sudan, 2007 and 2010. Emerg. Infect. Dis. 19(2), 246-253.

Ayari-Fakhfakh, E., Ghram, A., Bouattour, A., Larbi, I., Gribaa-Dridi, L., Kwiatek, O., Bouloy, M., Libeau, G., Albina, E. and Cetre-Sossah, C. 2011. 
First serological investigation of peste-des-petitsruminants and Rift Valley fever in Tunisia. Vet. J. 187, 402-404.

Caminade, C., Ndione, J.A., Diallo, M., MacLeod, D.A., Faye, O., Ba, Y.M., Dia, I. and Morse, A.P. 2014. Rift Valley fever outbreaks in Mauritania and related environmental conditions. Int. J. Environ. Res. Public Health 11, 903-918.

Cannon, R.M. and Roe, R.T. 1982. Livestock Disease Surveys: A Field Manual for Veterinarians. Canberra, Australia : Australian Government Pub. Service, 1982.

Davies, F.G., Linthicum, K.J. and James, A.D. 1985. Rainfall and epizootic Rift Valley fever. Bull. World Health Organ. 63, 941-943.

EFSA (European Food and Safety Authority). 2013. EFSA Panel on Animal Health and Welfare (AHAW); Scientific Opinion on Rift Valley fever. EFSA Journal 2013; 11(4), 3180. [48 pp.] doi:10.2903/j.efsa.2013.3180. Available online: www.efsa.europa.eu/efsajournal. Accessed 12 November 2017.

FAO (Food and Agricultural Organization of the United Nations). 2018. FAOSTAT: http://www.fao.org/faostat/en/\#data/EK. Accessed 25 November 2017.

Faye, O., Ba, H., Ba, Y., Freire, C.C., Faye, O., Nadiaye, O., Elgady, I.O., Zanotto, P.M., Diallo, M. and Sall, A.A. 2014. Reemergence of Rift Valley fever, Mauritania, 2010. Emerg. Infect. Dis. 20(2), 300-303.

Fontenille, D., Traoré-Lamizana, M., Diallo, M., Thonnon, J., Digoutte, J.P. and Zeller, H.G. 1998. New vectors of Rift Valley Fever in West Africa. Emerg. Infect. Dis. 4, 289-293.

Hassan, O.A., Ahlm, C., Sang, R. and Evander, M. 2011. The 2007 Rift Valley Fever Outbreak in Sudan. PLoS Negl. Trop. Dis. 5(9), e1229. doi: 10.1371 /journal.pntd.0001229.

Kamal, A.S. 2011. Observations on rift valley fever virus and vaccines in Egypt. Virol. J. 8, 532. doi: 10.1186/1743-422X-8-532.

LaBeaud, A.D., Muchiri, E.M., Ndzovu, M., Mwanje, M.T., Muiruri, S., Peters, C. and King, C.H. 2008. Inter-epidemic Rift Valley fever virus seropositivity, northeastern Kenya. Emerg. Infect. Dis. 14, 1240-1246.

Lichoti, J.K., Kihara, A., Oriko, A.A., Okutoyi, L.A., Wauna, J.O., Tchouassi, D.P., Tigoi, C.C., Kemp, S., Sang, R. and Mbabu, R.M. 2014. Detection of Rift Valley Fever Virus Inter-epidemic activity in some hotspot areas of Kenya by sentinel animal surveillance, 2009-2012. Vet. Med. Int. ID 379010. doi: $10.1155 / 2014 / 379010$.

Madani, T.A., Al-Mazrou, Y.Y., Al-Jeffri, M.H., Mishkhas, A.A., Al-Rabeah, A.M., Turkistani, A.M., Al-Sayed, M.O., Abodahish, A.A., Khan, A.S., Ksiazek, T.G. and Shobokshi, O. 2003. Rift valley fever epidemic in Saudi Arabia: epidemiological, clinical and laboratory characteristics. Clin. Infect. Dis. 37, 1084-1092.

Meegan, J.M. 1979. The Rift Valley fever epizootic in Egypt 1977-78. 1. Description of the epizzotic and virological studies. Trans. R. Soc. Trop. Med. Hyg. 73, 618-623.

Meegan, J.M., Khalil, G.M., Hoogstraal, H. and Adham, F.K. 1980. Experimental transmission and field isolation studies implicating Culex pipiens as a vector of Rift Valley fever virus in Egypt. Am. J. Trop. Med. Hyg. 29, 1405-1410.

Meegan, J. and Bailey, C.L. 1988. Rift Valley fever. In The arboviruses: Epidemiology and ecology, Ed., Monath T.P.: CRC Press Inc., Boca Raton, pp: 5176.

Monaco, F., Cosseddu, G.M., Doumbia, B., Madani, H., El Mellouli, F., Jiménez-Clavero, M.A., Sghaier, S., Marianneau P., Cetre-Sossah, C., Polci, A., Lacote., S., Lakhdar, M., Fernandez-Pinero, J., Nassim, C.S., Pinoni, C., Dondona, A. C., Gallardo, C., Bouzid, T., Conte, A., Bortone, G., Savini, G., Petrini, A. and Puech, L. 2015. First external quality assessment of molecular and serological detection of Rift Valley fever in the Western Mediterranean Region. PLoS One. 10(11), e0142129. doi: 10.1371/journal.pone.0142129.

Mroz, C., Gwida, M., El-Ashker, M., Ziegler, U., Homeier-Bachmann, T., Eiden, M. and Groschup, M.H. 2017. Rift Valley fever virus infections in Egyptian cattle and their prevention. Transbound. Emerg. Dis. 64, 2049-2058.

Pages, N., Huber, K., Cipriania, M., Chevallier, V., Conraths, F.J., Balenghien, T. and Goffredo, M. 2009. Scientific report submitted to EFSA on mosquitoes and mosquito-borne disease. 1-96.

Rissman, M., Eiden, M., El Mamy, B.O. and Isselmou, K. 2016. Serological and genomic evidence of Rift Valley fever virus during inter-epidemic periods in Mauritania. Epidemiol. Infect. 145, 1058-1068.

Smithburn, K.C., Haddow, A.J. and Gillett, J.D. 1948. Rift Valley fever; Isolation of the virus from wild mosquitoes. Br. J. Exp. Pathol. 29, 107-121.

WHO (World Health Organization). 2016. Disease Outbreak News. Rift Valley fever in Niger. http://www.who.int/csr/don/29-september-2016rift-valley-fever-niger/en/. Accessed on 15 November 2017. 